\title{
The books of the Lowe Collection
}

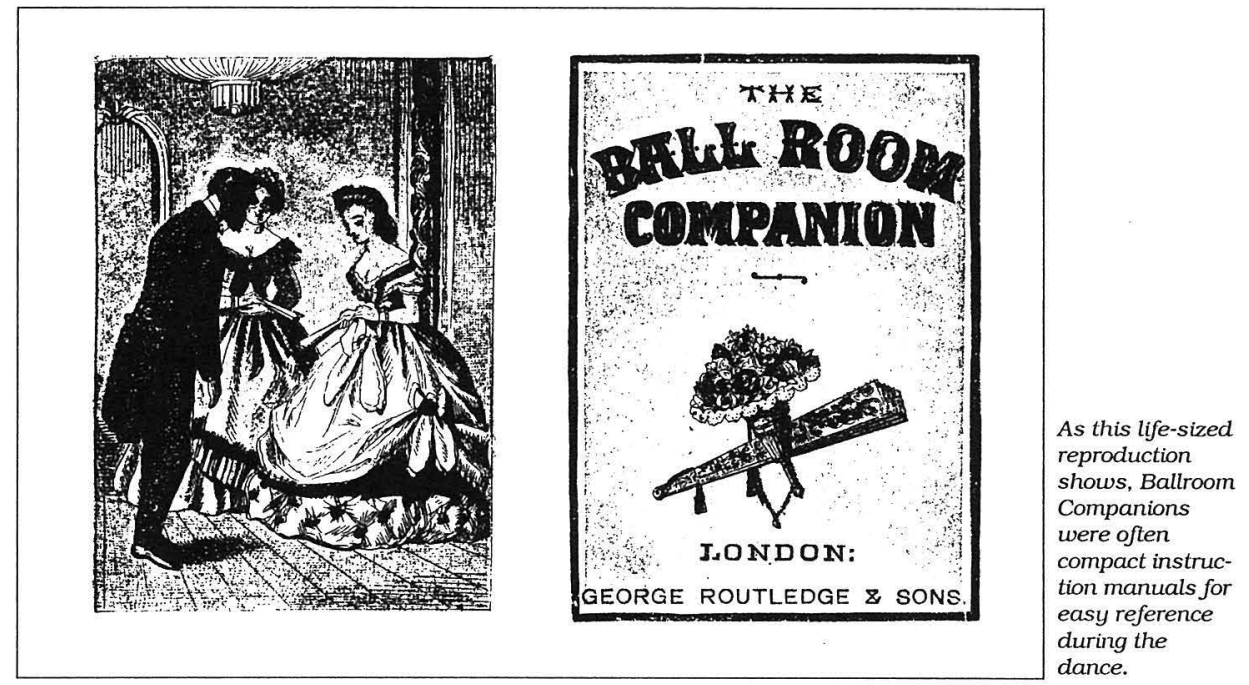

\section{RAE MARSHALL}

In addition to the three manuscripts the Lowe collection contains eight books, six of which were published in Britain and two in Australia. These can be considered in four groupings: Ballroom Companions (4), Dance history (1), Costume books (2), and Folk dance (1).

\section{1) BALLROOM COMPANIONS}

\section{Routledge's Ballroom Companion}

George Routledge \& Sons,

Camden Press,

London, no date

96 pages

Dancing As It Should Be

$10 \mathrm{~cm} \times 14 \mathrm{~cm}$

For Learners, Dancers and all Readers

by Edward Scott

W.H.Paling \& Co.

Sydney, no date [also revised edition, London, 1910]

110 pages

The Drawing Room Dances

$18 \mathrm{~cm} \times 13 \mathrm{~cm}$

by Cellarius

E. Churton Publisher,

London, 1847 [also published in French 1847

and reprinted 1870 New York]

149 pages

Robert's Manual of Fashionable Dancing $14 \mathrm{~cm} \times 9 \mathrm{~cm}$ George Robertson Publisher,

Melbourne, 1875

136 pages
These Ballroom Companions contain directions for the dances of polite society, and the requirements of good etiquette at balls and gatherings. They are typical of a myriad of such publications, which tended to borrow heavily on their predecessors one of which was Lowes' Ball-Conductor and Assembly Guide written by four Lowe brothers in the first decades of the 19th century (see illustration page 3 ).

Also present in the Lowe Book Collection is a tiny 13 page aide-memoire published by Joseph Eager Lowe in Melbourne. It is $6 \mathrm{~cm} \times 8.5 \mathrm{~cm}$ and is of strong card; it was actually worn at the wrist attached by a cord and could be consulted during the evening for details and variations of steps and figures of dances on the programme.

Several of the Companions begin with some history of dance, including comparison of theatre and ballroom forms. Preliminary information includes the proper salutations, the description of the ballroom (which is the top of the room where the leading couple stands), and the exercises 'deemed most important to give...ease to the body... [which] are to dance what solfa exercises are to song'(Robert's Manual of Fashionable Dancing, 18).

The toilette or style of dress is also dealt with. Gentlemen should wear: 'a black suit, thin enamelled boots, a 
white neckcloth, and white or delicate grey gloves...He may wear an embroidered shirt and his waistcoat may be of silk. White waistcoats are no longer fashionable. Ladies who dance should wear dresses of light diaphanous materials, such as tulle, gauze, crape, net etc over coloured silk slips. Silk dresses are not suitable for dancing... Very stout persons should never wear white. It has the effect of adding to the bulk of the figure'(Routledge's Ballroom Companion, 12).

In each of the Ballroom Companions specific dances are described. Only the waltz is present in the four Companions, in a number of variations including Waltz à trois temps and Waltz à deux temps - with three steps to the bar, and with two. The waltz-mazurka, or Cellarius, is one of the varieties described in Roberts; and in Cellarius's own book comes the modest disclaimer: 'My pupils would have this waltz called after me, and have it named the Cellarius. I have no choice but with all humility to accept this honour; to have declined it would, I think, have been on my part much more an affectation than an act of modesty. (The Drawing Room Dances, 74).

After discussion of different dance forms, two of the books turn to the musical arrangements necessary for a successful ball. Roberts places emphasis on choosing an orchestra : ' a musician, to make people dance, ought

\section{2) DANCE HISTORY}

\section{Dancing In All Ages}

By Edward Scott

Swan Sonnenschein \& Co Ltd London, 1899

$21 \mathrm{~cm} \times 14 \mathrm{~cm}$

208 pages

This book surveys the history of dance from its 'Nature and Origin' to 'Modern Dancing'. It commences with the dancing of ancient Egypt, the Greeks and ancient Rome; then follows a chapter on Religious, Mysterious or Fanatical elements in dancing which includes the 'Dance of Death'

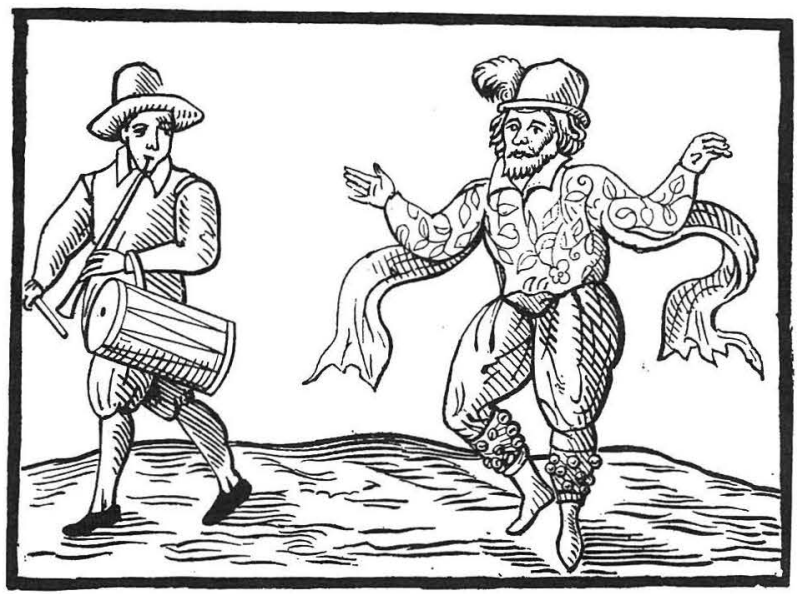

always to have a metronome at the end of his bow' (page 131). And in Edward Scott's Dancing as it should be short excerpts from popular dance music, mostly waltzes, are given, with the note : 'Admirers of Good Dance music are Politely requested to spend a few moments in perusing the following extracts from some of the most popular dances of the day' (page 101).

from Robert's

Manual of

Fashionable

Dancing

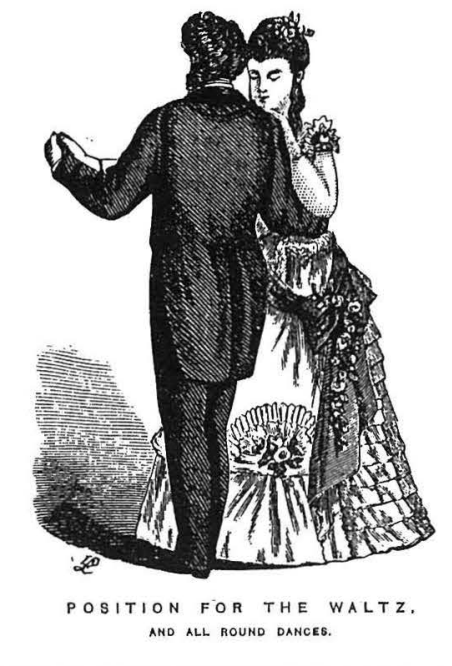

or 'Danse Macabre', the Dervishes of the east, and the unfortunate people who were attacked by the St Vitus's Dance in the 14th century.

ChapterVI entitled 'Remarkable Dances of LaterTimes' covers the period of Louis XIV and his patronage of the arts and includes the well known names of Molière, Lully, Provost, and Renaud. The chapter then moves to the ballroom discussing Pavane, Galliard, Volta and the Minuet. Chapter VII is devoted to the Minuet, its history and the reasons for its popularity, as well as the changes made over its years of pre-eminence.

In the final chapter 'Modern dancing' the author complains that 'the art of dancing has degenerated to such an extent that its practice, as frequently exhibited both in public and private, is a positive disgrace to the age (182). He deplores the lack of grace exhibited by young ladies and the vulgarity which is demonstrated. But he finally takes a hopeful rather than a despondent view that this is only a passing phase of an art which has already survived many similar periods of decline. $\mathrm{He}$ 'would fain conclude by expressing the hope, nay conviction, that dancing will sooner or later resume its ancient dignity, and be once more regarded not as a frivolous pastime, not merely as a recreative art, but as an art by which natural loveliness may be enhanced and life adorned' (200). 


\section{3) COSTUME BOOKS}

Gentlemen's Fancy Dress - How to Choose It $20 \mathrm{~cm} \times 14 \mathrm{~cm}$

By Adern Holt

Wyman \& Sons,

Lincolns-Inn Fields,

London, 1882

66 pages

Fancy Dress Described or What to Wear at Fancy Balls

$20 \mathrm{~cm} \times 14 \mathrm{~cm}$

By Adern Holt

Debenham \& Freebody

London, Fourth Edition, 1884

168 pages

Both these books describe fancy costumes from A- $Z$, the first book for men only, the second for men and women. Each has very complete descriptions of dress, including the types of material to be used (see illustration page 17).

Adern Holt also wrote a series of books giving instruction for the dances of the Renaissance and Baroque which are typical of the early dance revivals of the late 19th century.

\section{4) FOLK DANCE}

\section{The Morris Book}

$20 \mathrm{~cm} \times 13 \mathrm{~cm}$

A History of Morris dancing with a description of the eleven dances performed by the Morris men of England.

by Cecil Sharp and Herbert C. Macilwaine Novello \& Co

London 1907

80 pages

The history of Morris dancing from its origins to its hopeful renaissance at the date of publication of this book. It contains notation of figures and explicit descriptions of the Morris steps as well as special instructions for particular dances: Bean Setting Country Gardens, Constant Billy, Rigs 0' Marlow, Bluff King Hal, How D'ye Do, Shepherds Hey, Blue Eyed Stranger, Morris Off.

Cecil Sharp and his co-workers were tire-

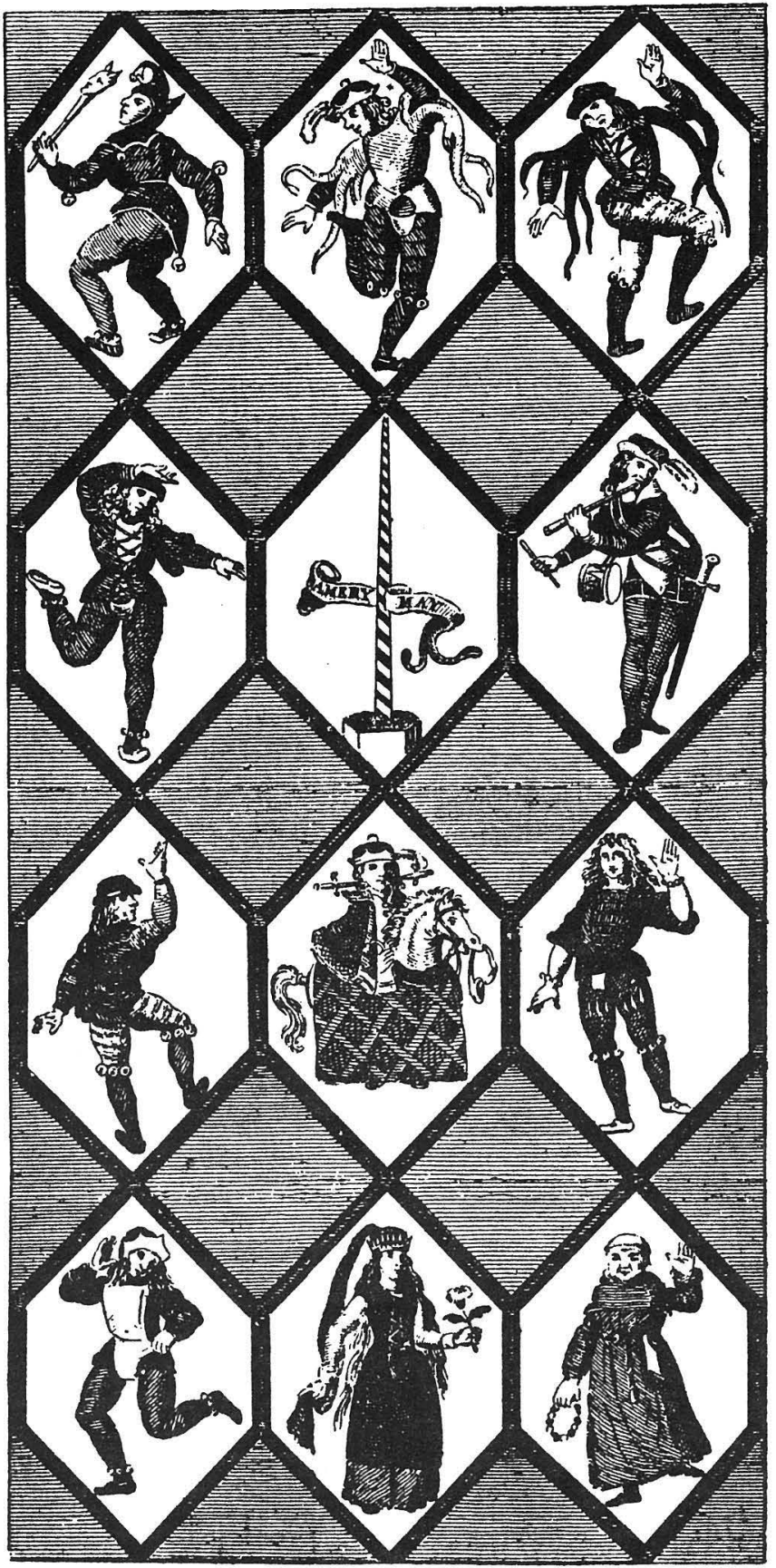

less in their efforts to recover and promote traditional folk music and dance. They directed attention to the rich traditions, and hoped for a revival of many forms.

Acknowledgement:

Elizabeth Aldrich, Historical Dance

Foundation, New York, gave

valuable biographical help
Morris dancers, as depicted in an oearly stained glass window in a house at Betley, Staffordshire 